\title{
THE IMPACT OF SOCIAL SUPPORT ON WORK ENGAGEMENT: THE MEDIATING ROLE OF \\ PSYCHOLOGICAL EMPOWERMENT
}

\author{
Manar A. Hamouda \\ Demonstrator \\ Faculty of Commerce \\ Alexandria University
}

\author{
Rawya M. Hassan
}

Associate Professor

Faculty of Commerce

Alexandria University

\author{
Wessam M. Khedr \\ Assistant Professor \\ Faculty of Commerce \\ Alexandria University
}

\begin{abstract}
The purpose of this study is to deepen the understanding of the psychological process leading to the effect of social support types (e.g. perceived organizational support, perceived supervisor support, perceived coworker support) on work engagement by testing the mediating role of psychological empowerment. It also attempts to treat social support types as separate constructs and test whether they have different effects on different work outcomes in a relatively disengaged, but under-researched, context as Egypt. Self-administered questionnaires were distributed to customer service banking employees. Structural Equation Modeling was used to test the hypothesized relationships across a sample size of 384 employees. Results revealed that psychological empowerment fully mediated the relationship between perceived supervisor support, perceived coworker support, and work engagement. It also partially mediated the relationship between perceived organizational support and work engagement. Furthermore, although only perceived organizational support has a direct positive effect on work engagement, the three types of support positively affect employees' psychological empowerment.
\end{abstract}

\section{الملخص:}

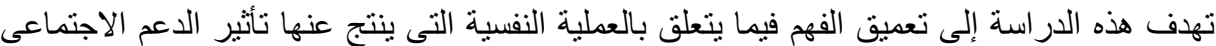

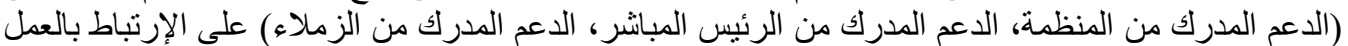

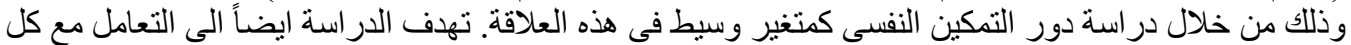

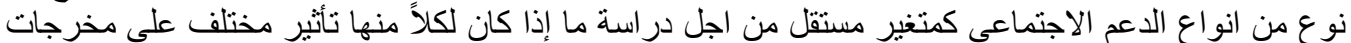

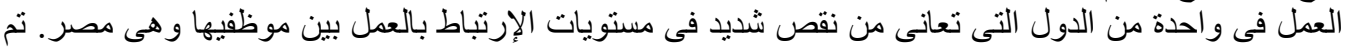

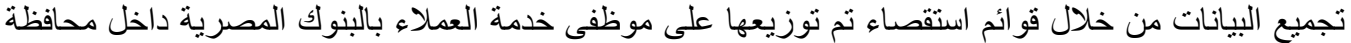

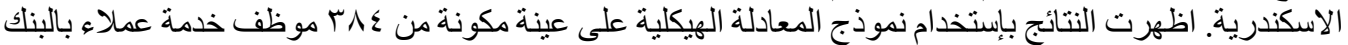

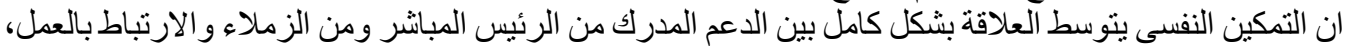

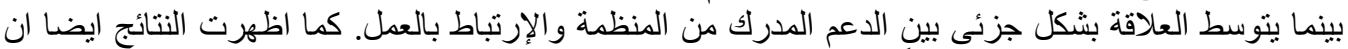

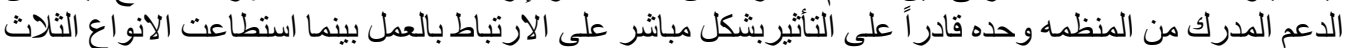

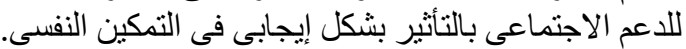




\section{Introduction}

In today's rapidly changing environment, having an engaged workforce creates a competitive advantage for any organization (Rich, Lepine \& Crawford, 2010). Organizations with excellent work engagement reported 3.9 times growth in earnings per share compared to those that reported low work engagement levels (Gallup, 2010). In contrast, disengaged employees cost an organization as they become less productive (Richman, 2006). Consequently, having an engaged workforce is considered the fourth most important management challenge facing companies (Aselstine \& Allestson, 2006).

Work engagement is a persistent, positive, affective-motivational state of fulfilment in employees that is characterized by energy, dedication and absorption (Schaufeli \& Bakker, 2004). Given its importance, an increasing number of studies examined factors that affect work engagement (e.g. Caesens, Stinglhamber \& Luypaert, 2014). Among these factors were social support types including Perceived Organizational Support (POS), Perceived Supervisor Support (PSS), and Perceived Coworker Support (PCS). Social support is part of the job resources; it refers to the extent to which organizations and supervisors value the contribution and well-being of their employees (Rhoades \& Eisenberger, 2002) and coworkers' willingness to help each other complete work-related tasks (Cureton, 2014).

Previous studies have indicated that each type of social support has its own effect on work outcomes; however, few have included them together in one study as separate constructs ( $\mathrm{Ng} \&$ Sorensen, 2008). Among these few studies, it was found that all three types of social support improve employees' job satisfaction ( $\mathrm{Ng} \&$ Sorensen, 2008) as well as employees' safety and health compliance behavior (Puah, Ong \& Chong, 2016). In both studies POS reported the highest effect on work outcomes compared to PSS and PCS. However, in Simosi's (2012) study, although it was still found that all types of social support enhanced affective commitment, PCS was not significant in raising normative commitment.

Moreover, studies that have examined the effect of the three types of social support on work engagement specifically, also recorded some nonuniformity in results. For example, in Ghosh, Rai and Singh's (2016) study, all the three types of social support had significant effect, with POS having the greatest effect. However, in Caesens et al.'s (2014) study it was found that only POS and PSS significantly affect work engagement, with PSS having higher effect.

Nevertheless, a review of the literature on studies focusing on one or two types of social support confirms the positive impact of POS on work engagement (e.g. Saks, 2006). However, inconsistency of results was witnessed among PSS and PCS. Some studies have failed to prove the significant effect of PSS and/or PCS on work engagement (e.g. Karatepe \& Olugbade, 2009; Inoue et al., 2013), 
whereas others are debatable regarding the relative importance of PSS and PCS to work engagement. Those who believe that PSS is more important consider it as a more stable resource to employees (Caesens et al., 2014), while PCS advocates believe that colleagues are the heart of social support (Cureton, 2014) and help combat health impairment symptoms (Simbula, 2010).

From the review above, it can be concluded that the few studies including the three social support types together, as well as those that concentrated on one or two types show that POS has a relatively higher consistency in its results compared to PSS and PCS. Accordingly, this research attempts to distinguish between the effects of each type of social support through including them in one study and examining their effect on work engagement.

Besides social support, other personal resources such as psychological empowerment in spite of its importance in raising employees' work engagement have been rarely investigated (Jose \& Mampilly, 2015). Psychological empowerment (including meaning, competence, self-determination, and impact) refers to a set of psychological states that are necessary for individuals to feel a sense of control in relation to their work (Spreitzer, Kizilos \& Nason, 1997). Unlike job resources, psychological empowerment leads to intrinsic motivation through employees' perception of empowerment. Hence, it is considered a personal belief rather than a job characteristic (Quinones, Van den Broeck \& De Witte, 2013).

Additionally, empowerment theorists view psychological empowerment as an explanatory mechanism through which contextual factors affect individuals' attitudes (Spreitzer et al., 1997). This can be attributed to the fact that psychological empowerment is a cognitive model that reflects people's perception toward themselves in relation to work environment based on individual differences (Spreitzer, 1995). Consequently, it can be argued that adding psychological empowerment as a mediator could help explain the social support effect on work engagement, and hopefully, their associated inconsistency.

Another point that has been raised in the work engagement literature is that it is predominantly Western-based (Dagher, Chapa \& Junaid, 2015). Explaining work engagement in different cultural contexts will add value to the established literature by comparing its results to other relatively new contexts, which will eventually help generalize the findings and broaden understanding of the engagement process. To fill this research gap, this study examines work engagement in Egypt.

Studying work engagement in Egypt is important because Egypt tends to have high propensity of disengaged employees; it alone accounted for 32 percent of disengaged employees in the Middle East region (Gallup, 2012). The disengagement problem in Egypt has been a crucial but under-resolved challenge. Factors such as autocratic management styles denoted by a high power distance 
culture have contributed to the disengagement status for many years (Hatem, 2006). In addition, with the recent economic and political unrest following the 2011 revolution, employees' attitudes toward their work have changed (El-Kot, 2016), their demands increased and the disengagement problem intensified, as reflected in 1969 strikes in 2012 compared to 530 in 2010 (Shukrallah \& Ali, 2013). Therefore, this study focuses on examining the effect of both social support and psychological empowerment in raising Egyptians' engagement within these conditions.

\section{Literature Review and Hypotheses Development}

\section{Social support and work engagement:}

According to the job demands-resources (JD-R) model, social support is part of the job resources provided to employees to help them control their job demands and perform their jobs effectively (Schaufeli \& Bakker, 2004). Job resources help satisfy employees' psychological needs and stimulate their motivation for learning and development (Schaufeli \& Salanova, 2007). Each type of social support is especially important for jobs requiring contact with customers because such jobs entail many job demands (Ng \& Sorensen, 2008).

Based on the organizational support theory; employees assign humanlike characteristics to their organizations and interpret good treatment as a sign of support to them (Rhoades \& Eisenberger, 2002). POS can help in fulfilling employees' socioemotional needs leading to an increased level of identification with the organizations and in turn increased job engagement (Kurtessis et al., 2017).

Regarding the effect of PSS and PCS, these two types of support have been handled differently by different researchers. Some researchers believe that they are complementary to POS and can be predictors to it and ultimately lead to positive work outcomes (e.g. Kurtessis et al., 2017). Others have treated them as one construct of "social support" reflecting the interpersonal support without distinguishing between supervisors' or coworkers' support (e.g. Alzyoud, Othman \& Isa, 2014). Yet, such an approach was criticized since it does not separate the effect of each concept on work outcomes (Ng \& Sorensen, 2008). Nevertheless, those who separated them as two constructs have had inconsistent results towards their effect on work outcomes. For example, although Quinones et al. (2013) found that both PSS and PCS raised work engagement, in Inoue et al.'s (2013) study both types failed to significantly affect work engagement.

Other researchers have debated the relative importance of PSS and PCS, where it was found that supervisors have the skills needed to provide an adequate level of support to employees (May, Gilson \& Harter, 2004). While others found that coworkers' support is more important because supervisors may not be always available to help like coworkers (Avery, McKay \& Wilson, 2007). 
This discrimination against the relative effect of the three types of social support on work engagement is apparent within the Egyptian culture. As a collectivistic country, Egyptians normally priorities social harmony over individual achievement and performance (Badran \& Youssef-Morgan, 2015); they place more value on the quality of relationships as their main source of satisfaction thereby reflecting the importance of coworkers' support (Hatem, 2006). The paternalistic culture manifested in the Egyptian supervisorsubordinate relationship is also expected to add another important value to PSS. Finally, the quality of organizational life and its role in shaping Egyptians' attitude toward their jobs reflects the importance of POS (Hatem, 2006).

Drawing on the previous discussion and agreeing with the majority of studies, indicating the positive impact of social support types on engagement, it is hypothesized that:

H1: Social support types (a) POS, (b) PSS, and (c) PCS will positively affect work engagement directly.

\section{Psychological Empowerment as a mediator:}

First: The relationship between social support types and psychological empowerment:

Psychological empowerment exists when employees feel that they have control over their life and work (Spreitzer, 1995). It has been acknowledged that psychological empowerment is therefore not a fixed personality attribute, but it consists of cognitions that are shaped by the work environment (Stander \& Rothmann, 2010). Based on the JD-R model and the conservation of resources theory; people tend to protect and accumulate resources and over time these resources generate other personal resources either to protect them from negative work events or enhance other positive work outcomes. Evidences have indicated that employees use their job resources including social support to accumulate personal resources like psychological empowerment to cope with job demands and raise work engagement (Xanthopoulou et al., 2007, 2009).

Additionally, a meta-analysis done after reviewing 49 studies revealed that when employees were supported from their peers, bosses and their organization, they felt valued and this improved their psychological empowerment levels (Seibert, Wang \& Courtright, 2011). Additionally, findings indicated that POS contributed in increasing psychological empowerment of employees in Iranian banks and that the PSS from leaders raised followers' psychological empowerment (Afzali, Arash-Motahari \& Hatami-Shirkouhi, 2014; Bordin, Bartram, Casimir, 2007). Also, among service workers, it was found that peer support is essential element for employees to feel psychologically empowered and without such supportive relationships; empowerment programs 
may fail (Corsun \& Enz, 1999). So, based on previous discussion; it is hypothesized that:

H2: Social support types (a) POS, (b) PSS, (c) PCS will positively affect psychological empowerment

Second: The relationship between psychological empowerment and work engagement:

Although the above discussion showed that psychological empowerment is a malleable construct that is affected by work environment (Stander \& Rothmann, 2010), it is also considered as part of employees' inner nature (Siegall $\&$ Gardner, 2000). The true benefit of empowerment will not be seen unless the employees perceive themselves as being empowered (Siegall \& Gardner, 2000).

It was found that psychological empowerment contributed significantly in enhancing work engagement levels among employees and that low engagement levels were associated with low psychological empowerment levels (Wang \& Liu, 2015). In similar vein, among bank employees, psychological empowerment was also found to improve employees' work engagement that in turns enhanced their job satisfaction (Hassan, ul Hassan \& Shoaib, 2014). Also, in Egypt, it was found that Egyptian institutions which successfully implemented the empowerment process, their employees' satisfaction and commitment levels to their jobs were raised (Ibrahem, Elhoseeny \& Mahmoud, 2013; Ibrahim, ElMagd \& Sayed, 2014). Therefore, based on this propensity, it is hypothesized that:

\section{engagement.}

H3: Psychological empowerment will positively affect work

Third: Psychological empowerment's mediating role between social support types and work engagement:

Studies concentrating on the relationship of social support and psychological empowerment on one hand (e.g. Jose \& Mampilly, 2015; Siegall \& Gardner, 2000) and psychological empowerment and work engagement on the other hand (e.g. Jose \& Mampilly, 2014) confirmed the psychological empowerment's important role in those relationships. Yet despite this significant importance, few have studied its mediating role between social support types and work engagement (Quinones et al., 2013).

Psychological empowerment was found to have higher probability to act as a mediator between different antecedents and affective reactions like work engagement (Maynard, Gilson \& Mathieu, 2012). For example, in Jose and Mampilly (2015) and Quinones et al.'s (2013) studies, adopting the conservation of resources approach has proven the psychological empowerment's ability as a personal resource in mediating the relationship between social support and work engagement. 
Furthermore, regarding the investigation of psychological empowerment, it appeared that psychological empowerment as a mediator was either studied as one overall construct (e.g. Jose \& Mampilly, 2015) or each of its dimensions was studied as separate constructs (e.g. Gagne, Senecal \& Koestner, 1997). However, the impact of psychological empowerment was found to be more effective than its dimensions as Maynard et al. (2012) demonstrated: "Employees benefit from psychological empowerment, but when considering the four dimensions independently, a complex pattern of relationships emerges" (p. 1248).

Although Maynard et al.'s (2012) argument seems to be relatively recent, previous research approached this conclusion. Gagne et al. (1997) demonstrated that psychological empowerment's dimensions mediated the relationship between job characteristics and intrinsic motivation except for "competence". Spreitzer et al. (1997) also examined the relationship between each of the four dimensions of psychological empowerment with satisfaction, strain, and stress across two samples; the results revealed that each dimension was related to at least one outcome but no single dimension was related to all outcomes. This can be attributed to the ability of some dimensions (e.g. meaning) in enhancing affective outcomes more than other dimensions (e.g. impact) that contributed to improving performance outcomes.

These studies show that the four dimensions of psychological empowerment are complementary to each other. Ignoring one of them or capitalizing on only one may limit the empowerment process and the desired outcomes may not be reached (Maynard et al., 2012). Therefore, it is hypothesized that:

H4: Psychological empowerment (as an overall construct) will mediate the relationship between social support types (a) POS, (b)PSS, (c)PCS and work engagement. 


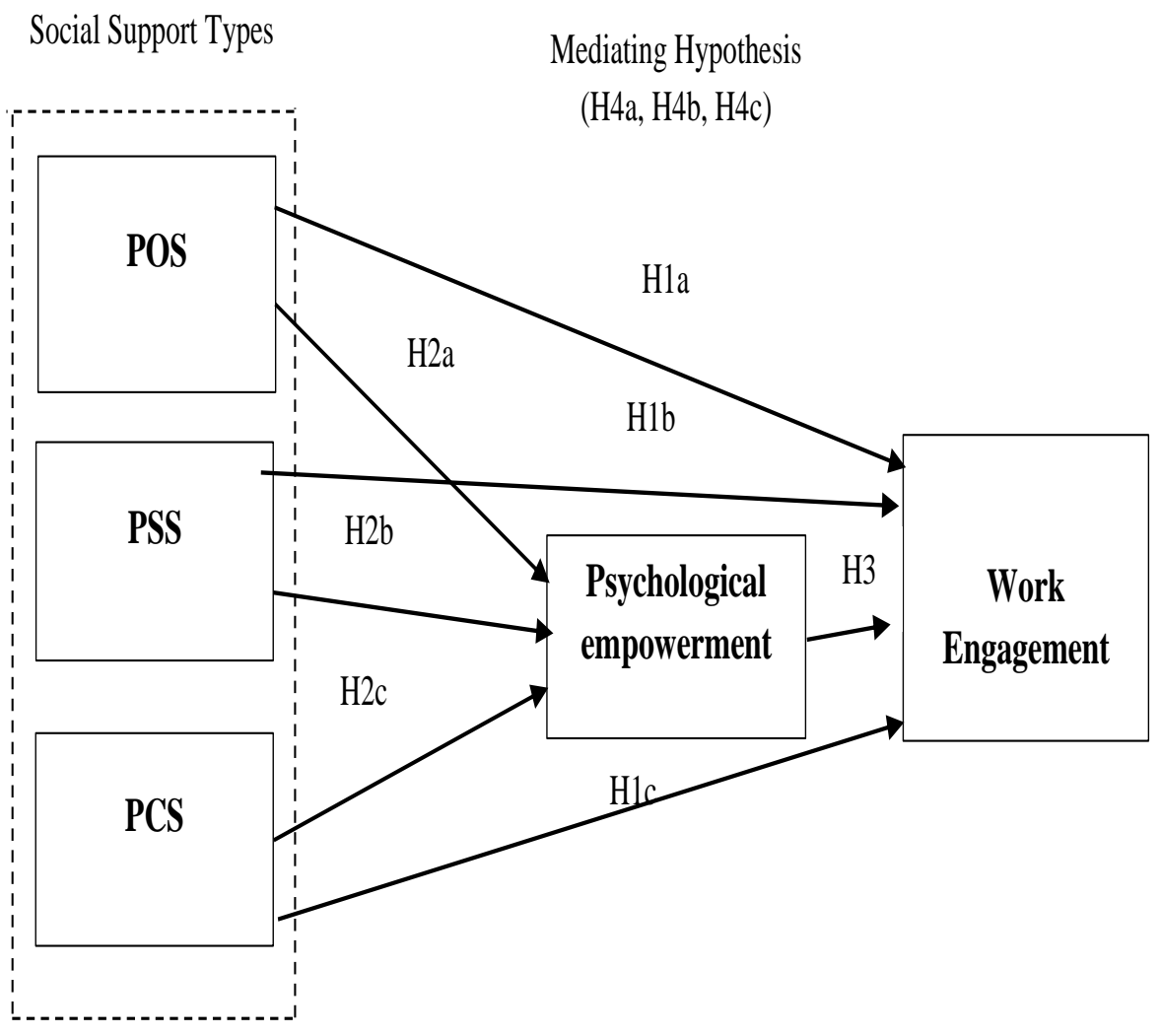

Figure (1): Research Framework

\section{Methodology:}

\section{Sample characteristics and procedures}

A cross-sectional design was used to conduct the current research in Alexandria, Egypt. According to the Central bank of Egypt's records, 39 banks with 247 branches were operating in Alexandria at the time of research. Among those; 35 banks ( 9 public and 26 private) agreed to participate. The data collection procedure started on 10/5/2016 and ended 20/8/2016. From 495 self- 
administered questionnaires distributed, 384 completed questionnaires were collected resulting in 77.5 percent response rate. Convenience sampling was employed due to difficulty obtaining a sampling frame of all employees (no access to databases was allowed due to strict rules of confidentiality set by banks).

It should also be noted that some employees were reluctant disclosing their personal information and most of the respondents refused to provide the bank's name because of the bank's private policy. According to Table I, and based on valid data entries, the sample is mostly males $(57.1 \%)$, working in private banks $(60.2 \%)$, with $26-30$ years old $(28.2 \%)$, and with 6-10 years of work experience $(31.8 \%)$ or more than 10 years $(31.8 \%)$.

Table I: Respondents' Demographic Characteristics

\begin{tabular}{|c|c|c|c|c|}
\hline Characteristics & Category & Frequency & Percentage & $\begin{array}{c}\text { Valid } \\
\text { Percentage } *\end{array}$ \\
\hline$\overline{\text { Gender }}$ & $\begin{array}{c}\text { Male } \\
\text { Female } \\
\text { N/A }\end{array}$ & $\begin{array}{c}216 \\
162 \\
6 \\
\end{array}$ & $\begin{array}{c}56.3 \% \\
42.2 \% \\
1.6 \% \\
\end{array}$ & $\begin{array}{c}57.1 \% \\
42.9 \% \\
- \\
\end{array}$ \\
\hline Age & $\begin{array}{c}21-25 \\
26-30 \\
31-35 \\
36-40 \\
41-45 \\
\text { More than } 45 \\
\text { N/A } \\
\end{array}$ & $\begin{array}{c}76 \\
107 \\
95 \\
27 \\
17 \\
58 \\
4 \\
\end{array}$ & $\begin{array}{c}19.8 \% \\
27.9 \% \\
24.7 \% \\
7 \% \\
4.4 \% \\
15.1 \% \\
1 \% \\
\end{array}$ & $\begin{array}{c}20 \% \\
28.2 \% \\
25 \% \\
7.1 \% \\
4.5 \% \\
15.3 \% \\
\\
\end{array}$ \\
\hline Experience & $\begin{array}{c}\text { Less than } 1 \text { year } \\
1-5 \text { years } \\
6-10 \text { years } \\
\text { More than } 10 \\
\text { years } \\
\text { N/A }\end{array}$ & $\begin{array}{c}40 \\
98 \\
121 \\
121 \\
4\end{array}$ & $\begin{array}{c}10.4 \% \\
25.5 \% \\
31.5 \% \\
31.5 \% \\
1 \%\end{array}$ & $\begin{array}{c}10.5 \% \\
25.8 \% \\
31.8 \% \\
31.8 \% \\
-\end{array}$ \\
\hline Private/ Public & $\begin{array}{c}\text { Private } \\
\text { Public } \\
\text { N/A }\end{array}$ & $\begin{array}{l}162 \\
107 \\
115\end{array}$ & $\begin{array}{l}42.2 \% \\
27.9 \% \\
29.9 \%\end{array}$ & $\begin{array}{c}60.2 \% \\
39.8 \% \\
-\end{array}$ \\
\hline
\end{tabular}

Note: $\mathrm{N}=384$; N/A: Missing values; *Percentage without missing values

\section{Measures}

Due to the fact that this research was carried in Egypt, all well-established scales that are used to measure the study variables were translated into Arabic. To make sure that those scales after their translations are still accurate, their reliabilities and validities were tested. First, the content validity was assessed using the back-translation method (Wang \& Lui, 2015), then the convergent and the discriminant validity were evaluated. Details on these methods are presented 
in the data analysis section. Finally, reliability was tested using Cronbach's alpha $(\alpha)$ coefficient; all items had acceptable values greater than 0.7 (Hair, Black, Babin \& Anderson, 2010).

\section{Work engagement}

Work engagement was assessed using the short version of the Utrecht Work Engagement Scale (UWES-9; Schaufeli, Bakker \& Salanova, 2006). The scale reflects three subscales including vigor (three items e.g. "At my work, I feel bursting with energy"), dedication (three items e.g. "My job inspires me"), and absorption (three items e.g. "I am immersed in my work"). A 7-point Likert-type scale from ' $0=$ Never' to ' $6=$ Always' was used. $(\alpha=0.93)$

\section{Psychological empowerment}

This was measured using Spreitzer's (1995) 12-item questionnaire. It was operationalized in terms of meaning (three items e.g. "The work I do is meaningful to me") ( $\alpha=0.79)$, competence (three items e.g. "I have mastered the skills necessary for my job") ( $\alpha=0.80)$, self-determination (three items e.g. "I have significant autonomy in determining how I do my job") $(\alpha=0.84)$, and impact (three items e.g. "My impact on what happens in my department is large") $(\alpha=0.84)$. Respondents rated each item on a 7-point Likert-type scale from ' $1=$ Strongly disagree' to ' $7=$ Strongly agree'.

\section{Perceived organizational support}

POS was measured using a short 8-item version of the perceived organizational support survey developed and validated by Eisenberger et al. (1997). Sample items include "My organization cares about my opinion." A 7-point Likert-type scale was used ranging from ' $1=$ Strongly disagree' to ' $7=$ Strongly agree'. $(\alpha=$ $0.90)$

\section{Perceived supervisor support}

It was assessed using Kottke and Sharafenski's (1988) 16-item measure. Sample items include "My supervisor appreciates extra effort from me." A 7-point Likert-type scale was used ranging from ' $1=$ Strongly disagree' to ' $7=$ Strongly agree'. $(\alpha=0.97)$

\section{Perceived coworker support}

It was assessed using Ladd and Henry's (2000) 9-item questionnaire. Sample items include "My coworkers really care about my well-being." Respondents rated each item on a 7 -point Likert-type scale from ' $1=$ Strongly disagree' to ' $7=$ Strongly agree'. $(\alpha=0.95)$ 


\section{Data analysis and Results:}

The researchers depended on exploratory factor analysis (EFA) using SPSS and confirmatory factor analysis (CFA) using AMOS software to conduct the validity and reliability tests and to test the research hypotheses using the Structural Equation Modeling method (SEM). Correlations, Cronbach's alpha as well as multi-collinearity were also checked for all variables. Finally, bootstrapping technique was used to test for mediation (Hayes, 2009).

\section{Convergent validity}

Convergent validity was assessed using EFA, as a pre-check step to prepare for the measurement model that was used later in AMOS (Anderson \& Gerbing, 1988). This step was done specifically to test for the dimensionality of work engagement, as it is sometimes treated as a single mutli-dimensional construct (e.g. Schaufeli et al., 2006), while other times used as uni-dimensional construct (e.g. Sonnentag, 2003). Results revealed that all items were loaded on their respective factors except for work engagement, which loaded on only one factor rather than three factors as the original measure assumes. Treating work engagement as a uni-dimensional construct is consistent with Sonnentag's (2003) findings. Even researchers (e.g. Bruin \& Henn, 2013) who demonstrated multidimensionality of work engagement, suggested that a total score is more justified because of the high correlation found between its dimensions.

Factor loadings of 0.5 as benchmark was employed (Fornell \& Larcker, 1981). This benchmark was used because according to Hair et al., (2010), researchers who normally approve the use of 0.3 as a minimum acceptable loading, believe that 0.4 is more important and 0.5 is very significant. Additionally, minimum factor loading of 0.3 is criticized as it ignores the influence of the sample size. EFA results revealed that three items were deleted from work engagement (one item from each of the proposed dimensions), two items from POS as well as PSS and one from PCS due to low loadings. The rest showed acceptable loading values (Table II).

Constructs reported average variance extracted (AVEs) $>50 \%$ which reflects a good representation of the indicators to the construct (Hair et al., 2010), where it ranged from $68.1 \%$ to $76.7 \%$. Also, CFA was developed using all highly loaded items in the EFA stage to confirm convergent validity. CFA also reported high loadings for the remaining items. The results of AVEs and factor loadings are reported in Table II. 
Table II: AVEs and Factor Loadings

\begin{tabular}{|c|c|c|c|}
\hline Variables & AVE\% & $\begin{array}{l}\text { EFA } \\
\text { Factor } \\
\text { Loading }\end{array}$ & $\begin{array}{l}\text { CFA } \\
\text { Factor } \\
\text { Loading }\end{array}$ \\
\hline Work Engagement: & $75.5 \%$ & & \\
\hline $\begin{array}{l}\text { WE1 } \\
\text { WE2 }\end{array}$ & & $\begin{array}{l}\mathbf{0 . 2 0 6} \\
0.806\end{array}$ & $\overline{0.743}$ \\
\hline WE3 & & 0.892 & 0.864 \\
\hline WE4 & & 0.052 & 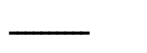 \\
\hline WE5 & & 0.887 & 0.864 \\
\hline WE6 & & 0.850 & 0.814 \\
\hline WE7 & & 0.276 & - \\
\hline WE8 & & 0.886 & 0.869 \\
\hline WE9 & & 0.890 & 0.882 \\
\hline POS: & $68.1 \%$ & & \\
\hline POS1 & & 0.835 & 0.775 \\
\hline POS2 & & 0.857 & 0.796 \\
\hline POS3 & & 0.876 & 0.865 \\
\hline POS4 & & 0.883 & 0.865 \\
\hline POS5 & & 0.727 & 0.667 \\
\hline POS6 $^{\mathrm{R}}$ & & 0.223 & - \\
\hline POS7 $^{\mathrm{R}}$ & & 0.317 & \\
\hline POS8 & & 0.760 & 0.708 \\
\hline PSS: & $74.3 \%$ & & \\
\hline PSS1 & & 0.833 & 0.810 \\
\hline PSS2 $^{\text {R }}$ & & 0.413 & \\
\hline PSS3 & & 0.841 & 0.822 \\
\hline PSS4 & & 0.873 & 0.867 \\
\hline PSS5 & & 0.896 & 0.888 \\
\hline PSS6 & & 0.857 & 0.835 \\
\hline PSS7 & & 0.883 & 0.865 \\
\hline PSS8 & & 0.902 & 0.892 \\
\hline PSS9 & & 0.871 & 0.860 \\
\hline PSS10 & & 0.824 & 0.811 \\
\hline PSS11 & & 0.905 & 0.904 \\
\hline PSS12 $^{\mathrm{R}}$ & & 0.164 & \\
\hline PSS13 & & 0.886 & 0.883 \\
\hline PSS14 & & 0.865 & 0.863 \\
\hline PSS15 & & 0.829 & 0.800 \\
\hline PSS16 & & 0.797 & 0.770 \\
\hline
\end{tabular}




\begin{tabular}{|c|c|c|c|}
\hline PCS: & $76.2 \%$ & & \\
\hline PCS1 & & 0.880 & 0.865 \\
\hline PCS2 & & 0.869 & 0.872 \\
\hline PCS3 & & 0.922 & 0.927 \\
\hline PCS4 & & 0.889 & 0.880 \\
\hline PCS5 & & 0.865 & 0.833 \\
\hline PCS6 & & 0.885 & 0.877 \\
\hline PCS7 $^{\mathrm{R}}$ & & $\mathbf{0 . 0 3 5}$ & \\
\hline PCS8 & & 0.833 & 0.777 \\
\hline PCS9 & & 0.838 & 0.783 \\
\hline \multicolumn{4}{|l|}{ Psychological Empowerment: } \\
\hline Meaning: & $71.1 \%$ & & 0.911 \\
\hline PE1 & & 0.835 & 0.711 \\
\hline PE8 & & 0.843 & 0.774 \\
\hline PE12 & & 0.853 & 0.771 \\
\hline Competence: & $71.9 \%$ & & 0.743 \\
\hline PE4 & & 0.856 & 0.743 \\
\hline PE6 & & 0.816 & 0.739 \\
\hline PE9 & & 0.872 & 0.805 \\
\hline Self-determination: & $76.7 \%$ & & 0.819 \\
\hline PE2 & & 0.824 & 0.688 \\
\hline PE5 & & 0.902 & 0.873 \\
\hline PE11 & & 0.898 & 0.863 \\
\hline Impact: & $75.9 \%$ & & 0.841 \\
\hline PE3 & & 0.794 & 0.652 \\
\hline PE7 & & 0.910 & 0.873 \\
\hline PE10 & & 0.904 & 0.888 \\
\hline
\end{tabular}

Notes: $\mathrm{N}=384 ; \mathrm{R}=$ Reversed question.

\section{Discriminant validity}

Discriminant validity was tested using AVE method. Results indicated that discriminant validity exists where the square roots of AVE for each construct were greater than its correlations (Anderson \& Gerbing, 1988, Farrell, 2010) as indicated in Table III. 
Table III: Discriminant Validity Result

\begin{tabular}{|c|c|c|c|c|c|c|c|c|c|c|}
\hline Variable & M & SD & 1 & 2 & 3 & 4 & 5 & 6 & 7 & 8 \\
\hline $\begin{array}{l}\text { 1. Work } \\
\text { engagement }\end{array}$ & 4.57 & 1.36 & $(0.87)$ & & & & & & & \\
\hline 2. POS & 4.56 & 1.49 & $.523(* *)$ & $(\mathbf{0 . 8 3})$ & & & & & & \\
\hline 3. PSS & 5.08 & 1.52 & $.531(* *)$ & $.703(* *)$ & $(0.86)$ & & & & & \\
\hline 4. PCS & 5.25 & 1.33 & $.439(* *)$ & $.538(* *)$ & $.531(* *)$ & $(0.87)$ & & & & \\
\hline 5. Meaning & 5.71 & .96 & $.608(* *)$ & $.477(* *)$ & $.504(* *)$ & $.479(* *)$ & $(0.84)$ & & & \\
\hline 6. Competence & 5.88 & 1.15 & $.343(* *)$ & $.253(* *)$ & $.286(* *)$ & $.320(* *)$ & $.611(* *)$ & $(0.85)$ & & \\
\hline $\begin{array}{l}\text { 7. Self- } \\
\text { determination }\end{array}$ & 6.19 & .852 & $.458(* *)$ & $.458(* *)$ & $.448(* *)$ & $.415(* *)$ & $.568(* *)$ & $.482(* *)$ & (.088) & \\
\hline 8. Impact & 5.25 & 1.40 & $.434(* *)$ & $.423(* *)$ & $.485(* *)$ & $.478(* *)$ & $.599(* *)$ & $.536(* *)$ & $.686(* *)$ & $(0.87)$ \\
\hline
\end{tabular}

Note: $\mathrm{N}=384$; $\mathrm{M}=$ Mean; $\mathrm{SD}=$ Standard Deviation; ** Correlation is significant at 0.01 level (2-

tailed); Square root of AVEs appear on the diagonal in parentheses.

Besides discriminant validity, multi-collinearity was checked using the variance inflation factor (VIF) and tolerance (TOL). Results proved that all independent variables do not have multi-collinearity problem as their tolerance values $>0.1$ and their VIF values $\leq 10$ (Field, 2009).

\section{Structural Equation Modeling and Hypotheses Testing:}

Several fit indices were assessed to ensure model fit to data. Incremental fit indices were used including the Tucker-Lewis index (TLI) and comparative fit index (CFI); their values $>0.9$. Standardized root mean squared residual (SRMR) and the root mean square of approximation (RMSEA) were used to measure the model absolute fit with cut-off values of $<0.08$ and $<0.07$ respectively, indicating a good fit. Finally, normed chi-square $\left(\chi^{2} / \mathrm{df}\right)$ also indicated a good parsimonious fit with a value between 1 and 3 . The full structural model showed acceptable fitting to data $\left(\chi^{2} / \mathrm{df}=2.488 ; \mathrm{df}=967\right.$; $\mathrm{SRMR}=0.0561 ; \mathrm{RMSEA}=0.062 ; \mathrm{CFI}=0.913 ; \mathrm{TLI}=0.907)$.

The research hypotheses were tested at a 95\% confidence level. Results pertaining to $\mathrm{H} 1$ indicated that POS had direct positive impact on work engagement $(\beta=0.231, p<0.05)$. However, both PSS $(\beta=0.120, p>0.05)$ and PCS $(\beta=0.019, p>0.05)$ did not have a significant effect on work engagement directly; which means that $\mathrm{H} 1$ is partially accepted. On the contrary, all three types of social support (POS: $\beta=0.159, p<0.05$; PSS: $\beta=0.315, p<0.001$; PCS: $\beta=0.287$, $\mathrm{p}<0.001$ ) positively affect psychological empowerment fully supporting $\mathrm{H} 2$ and psychological empowerment was found to positively affect work engagement 
( $\beta=0.424, \mathrm{p}<0.001)$ which supports $\mathrm{H} 3$ and allow for testing the mediating hypothesis.

Finally, bootstrapping technique was used to test the mediating hypothesis. The researchers performed 2000 bootstrap sample with $95 \%$ Bias corrected confidence intervals. Results indicated that $\mathrm{H} 4$ is accepted where psychological empowerment partially mediated the relationship between POS and work engagement as both the direct effect $(\beta=0.231, p<0.01)$ and the indirect effects $(\beta=0.068, p<0.05)$ are significant, while it fully mediates the relationship between PSS, PCS and work engagement where the direct effects (PSS: $\beta=0.120, p>0.05$; PCS: $\beta=0.019, \mathrm{P}>0.05$ ) are not significant with significant indirect effects (PSS: $\beta=0.134, \mathrm{P}<0.01$; PCS: $\beta=0.122, \mathrm{P}<0.01$ ). Bootstrapping results are indicated in Table IV.

Table IV: Bootstrapping Results:

\begin{tabular}{lccc}
\hline \hline Relationships & Direct effect & Indirect effect & Total effect \\
\hline \hline POS-PE-WE & $0.231^{* *}$ & $0.068^{*}$ & $0.299^{* *}$ \\
PSS-PE-WE & 0.120 & $0.134^{* *}$ & $0.254^{*}$ \\
PCS-PE-WE & 0.019 & $0.122^{* *}$ & 0.141 \\
\hline \hline
\end{tabular}

Notes: $\mathbf{N}=384 ;$ *P-value $<0.05 ; * * P-v a l u e<0.01$

\section{Discussion}

This paper aimed to test the effect of social support types (POS, PSS, PCS) on work engagement in the Egyptian workplace and whether psychological empowerment has a mediating role in these relationships. The findings showed that only POS has direct positive effect on work engagement while PSS and PCS failed to affect work engagement directly; confirming the argument that social support types are distinctive constructs and each has different effects on different work outcomes (Ng \& Sorensen, 2008).

The fact that POS was able to directly affect work engagement is consistent with grounded theories and models (e.g. Social exchange theory and JD-R model) and is supported by different studies (e.g. Caesen \& Stinglhamber, 2014). Regarding the insignificant effect of PSS and PCS, despite being inconsistent with the aforementioned theories and models, similar findings were detected in different contexts (e.g. Jose \& Mampilly, 2015).

The insignificant effect of PSS can be accounted for the fact that PSS is actually a reflection and predictor of POS (Eisenberger et al., 2002); therefore, the inclusion of POS in the model might have attenuated PSS direct effect on work engagement. Another explanation of such insignificant effect could be due to the possibility of the dominant high power distance culture (Hofstede, 2011) 
manifested in the unfriendly supervisor-subordinate relationship in the Egyptian workplace.

Regarding the insignificant effect of PCS, it is noted that Egyptians, despite being collectivistic in their social life, tend to be individualistic in business due to their need for power (Hatem, 2006). Furthermore, the examined sample seems to be occupied with very busy work schedules and a competitive environment, perhaps leading to limited time to establish strong relationships with their coworkers. This problem was found to be dominant among frontline employees in different jobs (Othman \& Nasrudin, 2013).

All types of social support were able to raise psychological empowerment and psychological empowerment as an intrinsic nature helped enhance work engagement. These results are consistent with the JD-R model, conservation of resources theory and self-determination theory as well as previous findings (e.g. Jose \& Mampilly, 2015).

Although detecting the relative power of each of the three types of social support on psychological empowerment is beyond the scope of this research, by comparing the beta values of the effect each type of social support on psychological empowerment further interesting results indicated that PSS has the greatest effect $(\beta=0.315)$ among different social support types on raising psychological empowerment which ensures that PSS is a more stable and critical resource for employees (Caesens et al., 2014; ) and specifically in Egypt where employees always resort to their managers for help and decision-making (Hatem, 2006).

Looking closely at the findings, the important role psychological empowerment plays as a mediator (fully with PSS and PCS, partially with POS) is evident. Generally, the psychological empowerment's mediating role is congruent with self-determination theory indicating that psychological needs satisfaction is essential for individuals to prosper and reach positive work outcomes and if support, especially from supervisors or coworkers, does not raise employees' feeling of empowerment, their effect on work engagement will disappear (Quinones et al., 2013). Additionally, this result goes favorably with other studies in Egypt showing that intrinsic benefits (e.g. social status) are more significant to Egyptians than extrinsic ones (e.g. attitude toward earning) (Badran $\&$ Youssef-Morgan, 2015). This result was also supported by other researchers demonstrating that social support and psychological empowerment complement each other (e.g. Jose \& Mampilly, 2015; Quinones et al., 2013).

The fact that psychological empowerment mediated the relationship (fully with PSS, PCS, partially with POS), could reflect the importance of the support brought by the organization versus colleagues' and supervisors' support. It seems that although employees need psychological empowerment to feel individuals' support, the support from their organization could be viewed a more crucial job resource to the extent that it holds its own individual effect beyond 
that gained via employees' empowerment perception. This could be due to the possibility that POS contributes to greater psychological well-being through satisfying employees' need for esteem and approval. Hence, it could solely enhance employees' positive feelings toward their jobs (Baran et al., 2012).

\section{Theoretical Implications}

This research is part of the growing body of studies that add to the literature of both psychological empowerment and work engagement. The research successfully covered some gaps introduced at the beginning of the paper. It included the three types of social support (POS, PSS, PCS) in one study and confirmed that each has different impact on work engagement. It also tested the current relationships in a non-western based country where there is a dearth of research regarding work engagement (Dagher et al., 2015).

However, the main contribution of the current study is investigating psychological empowerment's mediating role between social support types and work engagement. Although different studies showed that psychological empowerment and work engagement are important concepts in positive psychology and contribute to raising employees' well-being, few have investigated the mediating relationship (Quinones et al., 2013). The study indicated that psychological empowerment is an important personal resource that helps foster work engagement and without it; individuals' support effect on work engagement disappeared.

Although this research aimed to consider the three social support types together to denote the effect of each on work engagement and implicitly understand the inconsistent effect behind their results, this aim was not fully achieved. Nevertheless, the research corroborated with other studies upon POS importance on work outcomes and also used psychological empowerment besides other cultures and context specific reasoning to propose reasons for the results. However, the findings reveal the necessity for conduction of more research in different contexts.

\section{Practical Implications}

This research attempted to suggest tools to solve the overarching query posed at the beginning of the research. In order to raise Egyptian employees' work engagement, business employers should focus on enhancing social support and psychological empowerment.

Supervisors should note the importance of empowering their employees to assure that their support results in higher work engagement. Consequently, supervisors should be trained to apply different empowerment methods such as giving autonomy to their employees through consultation and delegation. Also providing feedback that might help employees master the skills necessary to do 
their job, and be more competent. Furthermore, it is thought that by allowing employees to participate in decision making will make them feel that they have impact on work outcomes (El-Kot \& Leat, 2008).

The same applies to coworkers' support. In order to raise work engagement, employees' feeling of empowerment should be raised; perhaps through working in teams and exchanging experiences that will ultimately raise employees' competences. Also, setting unified goals for employees promotes their sense of meaning to their job (Kurtessis et al., 2017).

More importantly, given the significant effect of POS on work engagement, organizations should focus on increasing POS. Therefore, organizations should listen to employees' opinions, care about their well-being and make an effort to support their goals and establish a prospering career with them through for example introducing new employees' relationship management systems. Also, training supervisors and coworkers to be more collaborative could be useful since they are reflection of organizational environment (Kurtessis et al., 2017).

\section{Limitations and Future Research}

Although the research has both theoretical as well as practical implications, it is not free of limitations. First, the researchers depended on a cross-sectional design rather than longitudinal one because the data collection procedure in developing countries is challenging and is hindered by routine, making longitudinal design an impossible option (Elahi, 2008). Moreover, other researchers in more developed countries safely used the cross-sectional design (Karanika-Murra, Duncan, Pontes \& Griffiths, 2015). However, cross-sectional designs may preclude strong statements of cause and effect. Nevertheless, the good fit of the study model may have somewhat attenuated this problem.

Second, depending on self-reported measures may lead to some bias in the obtained results and cause common method variance (CMV). However, CMV is less problematic when using validated scales, which is indicated by the validity and reliability tests conducted (Spector, 2006). Additionally, although the sample size is appropriate to the research objectives, the fact the sample is applied only across customer service banking employees limits the generalizability of the results. Moreover, AMOS does not allow for running analysis on missing data. Hence, controlling for demographic variables was not feasible due to having a number of missing entries resulting from respondents' reluctance in disclosing such information. Therefore, research results should be considered with some caution.

Furthermore, future studies may consider testing the role of outside support from family or friends in raising work engagement since such kinds of support were found to combat burnout (Blanch \& Aluja, 2012). Also, testing individuals' motives to empower others and the willingness to be empowered can 
provide valuable insights. Finally, replicating the current study in Egypt in the future within improved economic and political conditions may provide valuable comparative findings.

In conclusion, through examining social support types and detecting their effects on work engagement, as well as testing the psychological empowerment's mediating role among these relationships, this study has contributed to closing some gaps in literature and also highlighted others that remain present. More importantly, it suggested modifying some HR practices as a means to enhancing Egyptian workers' engagement.

\section{References}

Afzali, A., Arash Motahari, A., \& Hatami-Shirkouhi, L. (2014). Investigating the influence of perceived organizational support, psychological empowerment and organizational learning on job performance: an empirical investigation. Tehnički Vjesnik, 21(3), 623-629.

Alzyoud, A. A., Othman, S. Z., \& Isa, M. F. M. (2014). Examining the role of job resources on work engagement in the academic setting. Asian Social Science, 11(3),103-110.

Anderson, J. C., \& Gerbing, D. W. (1988). Structural equation modeling in practice: A review and recommended two-step approach. Psychological Bulletin, 103(3), 411-23.

Aselstine, K., \& Alletson, K. (2006). A new deal for the 21st century workplace. Ivey Business Journal, 70(4),1-9.

Avery, D. R., McKay, P. F., \& Wilson, D. C. (2007). Engaging the aging workforce: The relationship between perceived age similarity, satisfaction with coworkers, and employee engagement. Journal of Applied Psychology, 92(6), $1542-1556$.

Badran, M. A., \& Youssef-Morgan, C. M. (2015). Psychological capital and job satisfaction in Egypt. Journal of Managerial Psychology, 30(3), 354-370.

Baran, B. E., Shanock, L. R., \& Miller, L. R. (2012). Advancing organizational support theory into the twenty-first century world of work. Journal of Business and Psychology, 27(2), 123-147.

Bhatnagar, J. (2012). Management of innovation: role of psychological empowerment, work engagement and turnover intention in the Indian context. The International Journal of Human Resource Management, 23(5), 928-951. 
Blanch, A., \& Aluja, A. (2012). Social support (family and supervisor), workfamily conflict, and burnout: Sex differences. Human Relations, 65(7), 811833.

Bordin, C., Bartram, T., \& Casimir, G. (2007). The antecedents and consequences of psychological empowerment among Singaporean IT employees. Management Research News, 3(1), 34-46.

Caesens, G., \& Stinglhamber, F. (2014). The relationship between perceived organizational support and work engagement: The role of self-efficacy and its outcomes. Revue Européenne de Psychologie Appliquée/European Review of Applied Psychology, 64(5), 259-67.

Caesens, G., Stinglhamber, F., \& Luypaert, G. (2014). The impact of work engagement and workaholism on well-being: The role of work-related social support. Career Development International, 19(7), 813-35.

Corsun, D. L., \& Enz, C. A. (1999). Predicting psychological empowerment among service workers: The effect of support-based relationships. Human Relations, 52(2), 205-224.

Cureton, S. S. (2014). The Role of Exchange Ideology in Coworker Social Support and Work Engagement (Doctoral dissertation). Retrieved from http://aquila.usm.edu/dissertations/15

Dagher, G., Chapa, O., \& Junaid, N. (2015). The historical evolution of employee engagement and self-efficacy constructs: An empirical examination in a nonwestern country. Journal of Management History, 21(2), 232-56.

de Bruin, G. P., \& Henn, C. M. (2013). Dimensionality of the 9-item Utrecht Work Engagement Scale (UWES-9), Psychological Reports, 112(3), 788-99.

Eisenberger, R., Cummings, J., Aemeli, S., \& Lynch, P. (1997). Perceived organizational support, discretionary treatment, and job satisfaction. Journal of Applied Psychology, 82(5), 812-20.

Eisenberger, R., Huntington, R., Hutchison, S., \& Sowa, D. (1986). Perceived organizational support. Journal of Applied Psychology, 71(3), 500-507.

Eisenberger, R., Stinglhamber, F., Vandenberghe, C., Sucharski, I. L., \& Rhoades, L. (2002). Perceived supervisor support: contributions to perceived organizational support and employee retention. Journal of Applied Psychology, 87(3), 565-73. 
Elahi, A. (2008). Challenges of Data Collection: with Special Regard to Developing Countries, in Statistics, Knowledge and Policy 2007 Measuring and Fostering the Progress of Societies: OECD Publishing. Istanbul, Turkey, pp.297-304.

El-Kot, G. (2016). Human resource management in Egypt, in Budhwar P. and Mellahi, K., Managing Human Resources in the Middle East, Routledge, London and New York, pp.205-225.

El-Kot, G., \& Leat, M. (2008). Employees' perceptions of supervisory facets: An investigation within an Egyptian context. International Journal of Islamic and Middle Eastern Finance and Management, 1(2),149-165.

Farrell, A. M. (2010). Insufficient discriminant validity: A comment on Bove, Pervan, Beatty, and Shiu (2009). Journal of Business Research, 63(3), 324-327.

Field, A. (2009). Discovering Statistics Using SPSS, $3^{\text {rd }}$ ed., SAGE publications.

Fornell, C., \& Larcker, D. F. (1981). Evaluating structural equation models with unobservable variables and measurement error. Journal of Marketing Research, XVIII, 39-50.

Gagné, M., Senecal, C. B., \& Koestner, R. (1997). Proximal job characteristics, feelings of empowerment, and intrinsic motivation: A multidimensional model. Journal of Applied Social Psychology, 27(14), 1222-1240.

Gallup, Inc. (2010). Employee Engagement: What's Your Engagement Ratio? Washington, DC.

Gallup, Inc. (2012). State of the Global Workplace: Employee Engagement Insights for Business Leaders Worldwide. Washington, DC.

Ghosh, P., Rai, A., \& Singh, A. (2016). Support at Work to Fuel Engagement: A Study of Employees of Indian Banking Sector. Review of Integrative Business and Economics Research, 5(2),1-10.

Gkorezis, P., \& Petridou, E. (2012). The effect of extrinsic rewards on public and private sector employees' psychological empowerment: a comparative approach. The International Journal of Human Resource Management, 23(17), 35963612 .

Goodale, J. C., Koerner, M., \& Roney, J. (1997). Analyzing the impact of service provider empowerment on perceptions of service quality inside an organization. Journal of Quality Management, 2(2),191-215. 
Hair, J. F. J., Black, W. C., Babin, B. J., \& Anderson, R. E. (2010). Multivariate Data Analysis. $7^{\text {th }}$ ed., Prentice Hall International, NY.

Hassan, S., ul Hassan, M., \& Shoaib, M. (2014). Measuring the impact of perceived organization support, psychological empowerment and rewards on employees' satisfaction: Testing the mediating impact of employee engagement. World Applied Sciences Journal, 30(5), 652-660.

Hatem, T. (2006). Human resource management in Egypt. in Budhwar P. \& Mellahi, K., Managing Human Resources in the Middle East, Routledge, London and New York, pp.199-218.

Hayes, A.F. (2009). Beyond Baron and Kenny: Statistical mediation analysis in the new millennium. Communication Monographs, 79(4), 408-420.

Hofstede, G. (2011). Dimensionalizing Cultures: The Hofstede Model in Context. Online Readings in Psychology and Culture, 2(1), 1-8.

Ibrahem, S. Z., Elhoseeny, T., \& Mahmoud, R. A. (2013). Workplace empowerment and organizational commitment among nurses working at the Main University Hospital, Alexandria, Egypt. The Journal of The Egyptian Public Health Association, 88(2), 90-96.

Ibrahim, M. M., El-Magd, M. H. A., \& Sayed, H. Y. (2014). Nurse's psychological empowerment and perceived autonomy in university and teaching hospitals at Menofia Governorate/Egypt. Journal of Nursing Education and Practice, 4(9), 59-68.

Inoue, A., Kawakami, N., Tsuno, K., Shimazu, A., Tomioka, K., \& Nakanishi, M. (2013) Job demands, job resources, and work engagement of Japanese employees: A prospective cohort study. International Archives of Occupational and Environmental Health, 86(4), 441-49.

Jose, G., \& Mampilly, S. R. (2014). Psychological empowerment as a predictor of employee engagement: An empirical attestation. Global Business Review, 15(1), 93-104.

Jose, G., \& Mampilly, S. R. (2015). Relationships among perceived supervisor support, psychological empowerment and employee engagement in Indian workplaces. Journal of Workplace Behavioral Health, 30(3), 231-50.

Karanika-Murray, M., Duncan, N., Pontes, H. M., and Griffiths, M. D. (2015). Organizational identification, work engagement, and job satisfaction. Journal of Managerial Psychology, 30(8), 1019-33. 
Karatepe, O. M., \& Olugbade, O. A. (2009). The effects of job and personal resources on hotel employees' work engagement. International Journal of Hospitality Management, 28(4), 504-12.

Kline, R. B. (2011). Principles and practice of structural equation modeling, $3^{\text {rd }}$ ed, Guilford publications, New York, NY.

Kottke, J. L., \& Sharafinski, C. E. (1988). Measuring perceived supervisory and organizational support", Educational and Psychological Measurement, 48(4),1075-79.

Krejcie, R. V., \& Morgan, D. W. (1970). Determining sample size for research activities. Educational and Psychological Measurement, 30(3), 607-10.

Kurtessis, J. N., Eisenberger, R., Ford, M. T., Buffardi, L. C., Stewart, K. A., \& Adis, C. S. (2017). Perceived organizational support: A meta-analytic evaluation of organizational support theory. Journal of Management, 43(6),1854-1884.

Ladd, D., \& Henry, R. A. (2000). Helping coworkers and helping the organization: The role of support perceptions, exchange ideology, and conscientiousness. Journal of Applied Social Psychology, 30(10), 2028-49.

May, D. R., Gilson, R. L., \& Harter, L. M. (2004). The psychological conditions of meaningfulness, safety and availability and the engagement of the human spirit at work. Journal of Occupational and Organizational Psychology, 77(1), 1137.

Maynard, M. T., Gilson, L. L., \& Mathieu, J. E. (2012). Empowerment-fad or fab? A multilevel review of the past two decades of research. Journal of Management, 38(4), 1231-81.

Ng, T. W., \& Sorensen, K. L. (2008). Toward a further understanding of the relationships between perceptions of support and work attitudes: A metaanalysis. Group \& Organization Management, 33(3), 243-68.

Olivier, A. L., \& Rothmann, S. (2007). Antecedents of work engagement in a multinational company. SA Journal of Industrial Psychology, 33(3), 49-56.

Othman, N., \& Nasurdin, A. M. (2013). Social support and work engagement: A study of Malaysian nurses. Journal of Nursing Management, 21(8), 10831090 .

Puah, L. N., Ong, L. D., \& Chong, W. Y. (2016). The effects of perceived organizational support, perceived supervisor support and perceived co-worker 
support on safety and health compliance. International Journal of Occupational Safety and Ergonomics, 22(3), 333-339.

Quiñones, M., Van den Broeck, A., \& De Witte, H. (2013). Do job resources affect work engagement via psychological empowerment? A mediation analysis. Journal of Work and Organizational Psychology, 29(3), 127-134.

Rhoades, L., \& Eisenberger, R. (2002). Perceived organizational support: A review of the literature. Journal of Applied Psychology, 87(4), 698-714.

Rich, B. L., Lepine, J. A., \& Crawford, E. R. (2010). Job engagement: Antecedents and effects on job performance. Academy of Management Journal, 53(3), 617-635.

Richman, A. (2006). Everyone wants an engaged workforce how can you create it?. Work span, 49(1), pp.36-39.

Saks, A. M. (2006). Antecedents and consequences of employee engagement. Journal of Managerial Psychology, 21(7), 600-19.

Segars, A. H. (1997). Assessing the unidimensionality of measurement: A paradigm and illustration within the context of information systems research. Omega, 25(1), 107-121.

Schaufeli, W. B., \& Bakker, A. B. (2004). Job demands, job resources, and their relationship with burnout and engagement: A multi-sample study. Journal of Organizational Behavior, 25(3), 293-315.

Schaufeli, W. B., Bakker, A. B., \& Salanova, M. (2006). The measurement of work engagement with a short questionnaire: A cross-national study. Educational and Psychological Measurement, 66(4), 701-16.

Schaufeli, W.B. \& Salanova, M. (2007). Work engagement. An emerging psychological concept and its implications for organizations. in S. W. Gilliland, D. D. Steiner, and D. P. Skarlicki, Research in Social Issues in Management: Vol.5. Managing Social and Ethical Issues in Organizations, Information Age Publishers, Greenwich, CT, pp.135-177.

Seibert, S. E., Wang, G., \& Courtright, S. H. (2011). Antecedents and consequences of psychological and team empowerment in organizations: A metaanalytic review. Journal of Applied Psychology, 96(5), 981-1003.

Shukrallah, S., \& Ali, R. (2013). Post-revolution labour strikes, Social Struggles on Rise in Egypt: Report. Retrieved from http://english.ahram.org.eg/News/70384.aspx 
Shusha, A. A. (2013). The role of psychological engagement in relationship between perceived organizational support and withdrawal behavior and intentions: An empirical study on small industries in Egypt. International Journal of Business and Management, 8(16), 22-29.

Siegall, M., \& Gardner, S. (2000). Contextual factors of psychological empowerment. Personnel Review, 29(6), 703-722.

Simbula, S. (2010). Daily fluctuations in teachers' well-being: A diary study using the Job Demands-Resources model. Anxiety, Stress, \& Coping, 23(5), 563-584.

Simosi, M. (2012). Disentangling organizational support construct: The role of different sources of support to newcomers' training transfer and organizational commitment. Personnel Review, 41(3), 301-320.

Spector, P.E. (2006). Method variance in organizational research: Truth or urban legend?. Organizational Research Methods, 9(2), 221-32.

Spreitzer, G. M. (1995). Psychological empowerment in the workplace: Dimensions, measurement, and validation. Academy of Management Journal, $38(5), 1442-65$.

Spreitzer, G. M., Kizilos, M. A., \& Nason, S. W. (1997). A dimensional analysis of the relationship between psychological empowerment and effectiveness, satisfaction, and strain. Journal of Management, 23(5), 679-704.

Stander, M. W., \& Rothmann, S. (2010). Psychological empowerment, job insecurity and employee engagement. SA Journal of Industrial Psychology, $36(1), 1-8$.

Wang, S., \& Liu, Y. (2015). Impact of professional nursing practice environment and psychological empowerment on nurses' work engagement: Test of structural equation modeling. Journal of Nursing Management, 23(3), 287-296.

Xanthopoulou, D., Bakker, A. B., Demerouti, E., \& Schaufeli, W. B. (2009). Reciprocal relationships between job resources, personal resources, and work engagement. Journal of Vocational Behavior, 74(3), 235-244.

Xanthopoulou, D., Bakker, A. B., Demerouti, E., \& Schaufeli, W. B. (2007). The role of personal resources in the job demands-resources model. International Journal of Stress Management, 14(2), 121-41. 